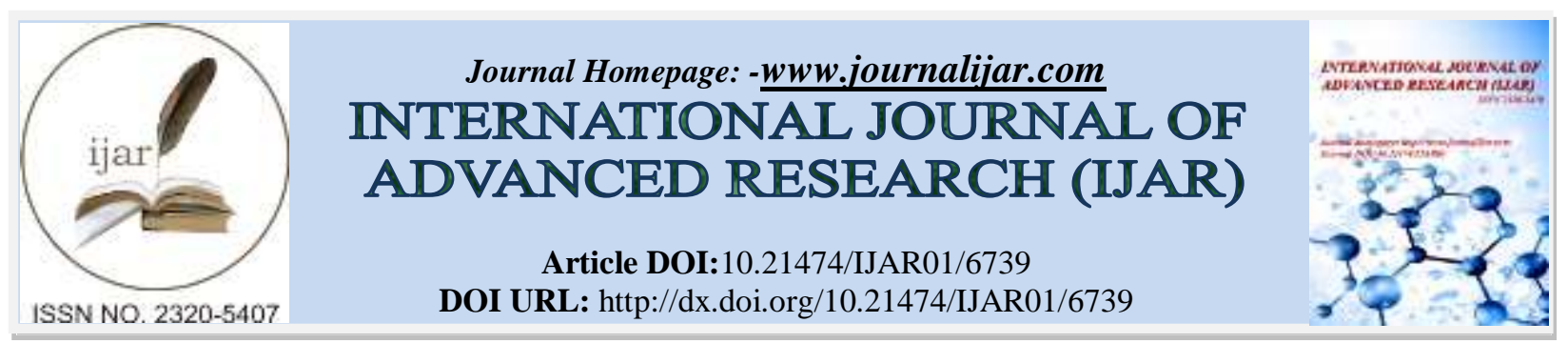

RESEARCH ARTICLE

\title{
WORKER'S HEALTH ASSESSMENT AND OCCUPATIONAL RISK FACTORS IN THE MEAT INDUSTRY.
}

\author{
Dr. Iurie Pinzaru. \\ National Centre of Public Health, Republic of Moldova, Chisinau.
}

\section{Manuscript Info}

Manuscript History

Received: 13 January 2018

Final Accepted: 15 February 2018

Published: March 2018

Keywords:-

Meat Processing Enterprises, Temporary

Disability, Occupational Risk Factors,

Hygienic Conditions.

\begin{abstract}
Health assessment of employees, as well as assessment of hygienic conditions was carried out at four meat processing enterprises in the Republic of Moldova during the 2011-2015. Indexes of frequency and duration of temporary disability were variables with a tendency to lowering. The index of diseases frequency showed an average annually decrease of 6.7 cases per 100 workers $\left(R^{2}=0,95\right)$, and the index of disease duration of 77 days per 100 workers $\left(R^{2}=0,95\right)$. The annual average increase of the mean disease duration with temporary incapacity per one case was 0.3 days. The occupational environment of the meat industry was characterized by a complex of unfavorable risk factors (microclimatic parameters, noise exposure), negatively influencing the workers' health. The morbidity features indicated the need to develop and to implement measures for improving the working conditions and reducing the impact of the occupational risk factors on health.
\end{abstract}

Copy Right, IJAR, 2018,. All rights reserved.

\section{Introduction:-}

Occupational exposure remains the basic contact through different agents resulting from the performance of a meat processing worker's duties. The study of occupational risk factors in the meat industry is of particular importance for the development of measures to improve occupational conditions and to maintain the workers health. The work in the meat industry is associated with health hazards that can result in occupational disease or may aggravate the existing health of nonoccupational origin (Banjo T.A. et.al., 2013; Campbell D.S., 1999; Health and Safety Guidance Notes for the Meat Industry, 2014; Harmse L. Johannes, 2016; WHO. Media centre 2014).

The impact of occupational hazard factors on health depends on hygienic factors of the occupational area as well as the intensity and tension of labor process. The workers of meat industry are exposed to several occupational health hazards namely: low temperatures and relative air humidity, the high noise exposure, the presence of biological and parasitological factors, etc. (Picard M., 2008; Pascolini D., 2009). Studies (Berry J. van Holland, 2015; Hristova Lidiya, 2016; McLean D., 2004; Rodilla José María Ramada, 2016; Shaprov M.N., 2013) have shown that working conditions in the meat industry contribute to the development of musculoskeletal, respiratory systems diseases and have a negative impact on the workers life quality and increasing health care costs. Scientific data connected with the study of occupational health hazards and risk assessment of the meat workers in Republic of Moldova is very limited. 
This study was conducted with the aim to assess the hygienic conditions and workers health in the meat-processing enterprises.

\section{Materials and methods:-}

The study was performed during 2012-2017 years. Data were collected in the four meat industry enterprises. Working conditions have been studied in 730 workplaces at three indicators: air temperature, relative air humidity and speed movement of air with use of the device "Testo EaSy Climate". 2190 tests have been carried out. With the use of the device for measurement of noise and vibration 540 measurements during all technological process have been performed. The methodical recommendation "Hygienic evaluation of the occupational environment factors and the work process" was applied. Hygiene criteria for classification of working conditions", approved by the Ministry of Health of the Republic of Moldova, no. 01.1032.3-1 of 10.03.2008, was used. Statistical data processing is carried out with use of the Microsoft Excel 2013 program, package of analysis - VBA.

\section{Results and discussions:-}

Hygienic assessment of microclimatic conditions in the occupational area indicated that in $54.8 \%$ of the cases the air temperature was below the sanitary norms (production areas - $65.7 \%$ and auxiliary $-32.1 \%$ ). The high humidity was registered in $84.0 \%$ (production areas: boning, filling of sausages - $90.3 \%$ and auxiliary - $70.9 \%$ ). It should be mentioned that speed movement of air did not exceed the acceptable limit of $0.4 \mathrm{~m} / \mathrm{s}$. The microclimate parameters that exceed the sanitary norms were registered at enterprises 1 and 3 (air temperature: 83.1\% and 81.8\%, respectively; humidity - 100\%). The lowest levels of the air temperature were registered at the enterprise 4 , where were $28.2 \%$ and the relative humidity parameters were $69.1 \%$ (figure 1 ).

It is obvious that microclimatic parameters generally depend on technological process of meat production for which lower temperatures and relative air humidity are characteristic.

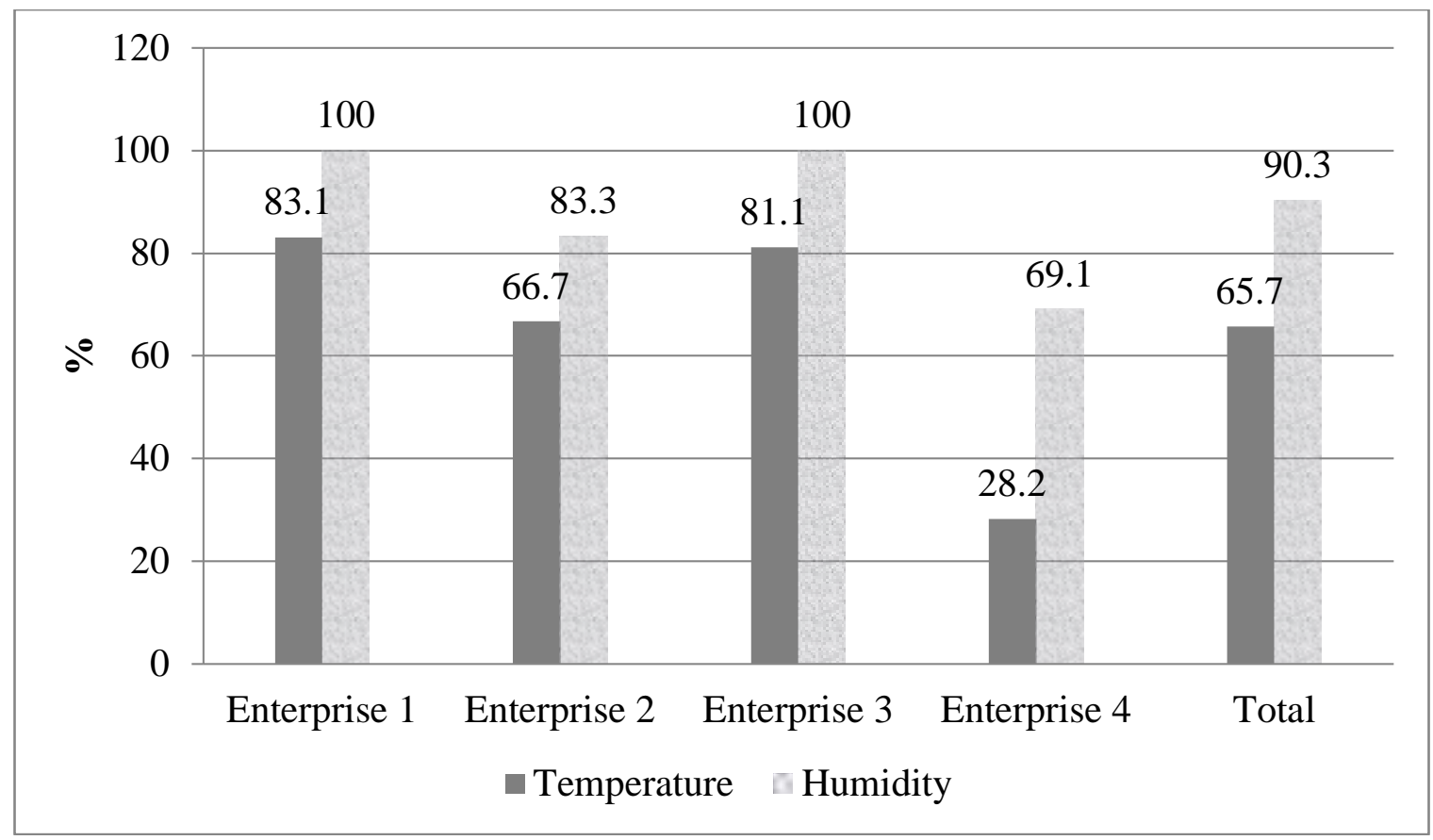

Fig.1:- The microclimate parameters in the meat enterprises (\%)

The highest air temperature and relative air humidity in workplaces which do not correspond to the sanitary norms were established in the cutting segment: $77.4 \%$ and $96.4 \%$ respectively (figure 2). 


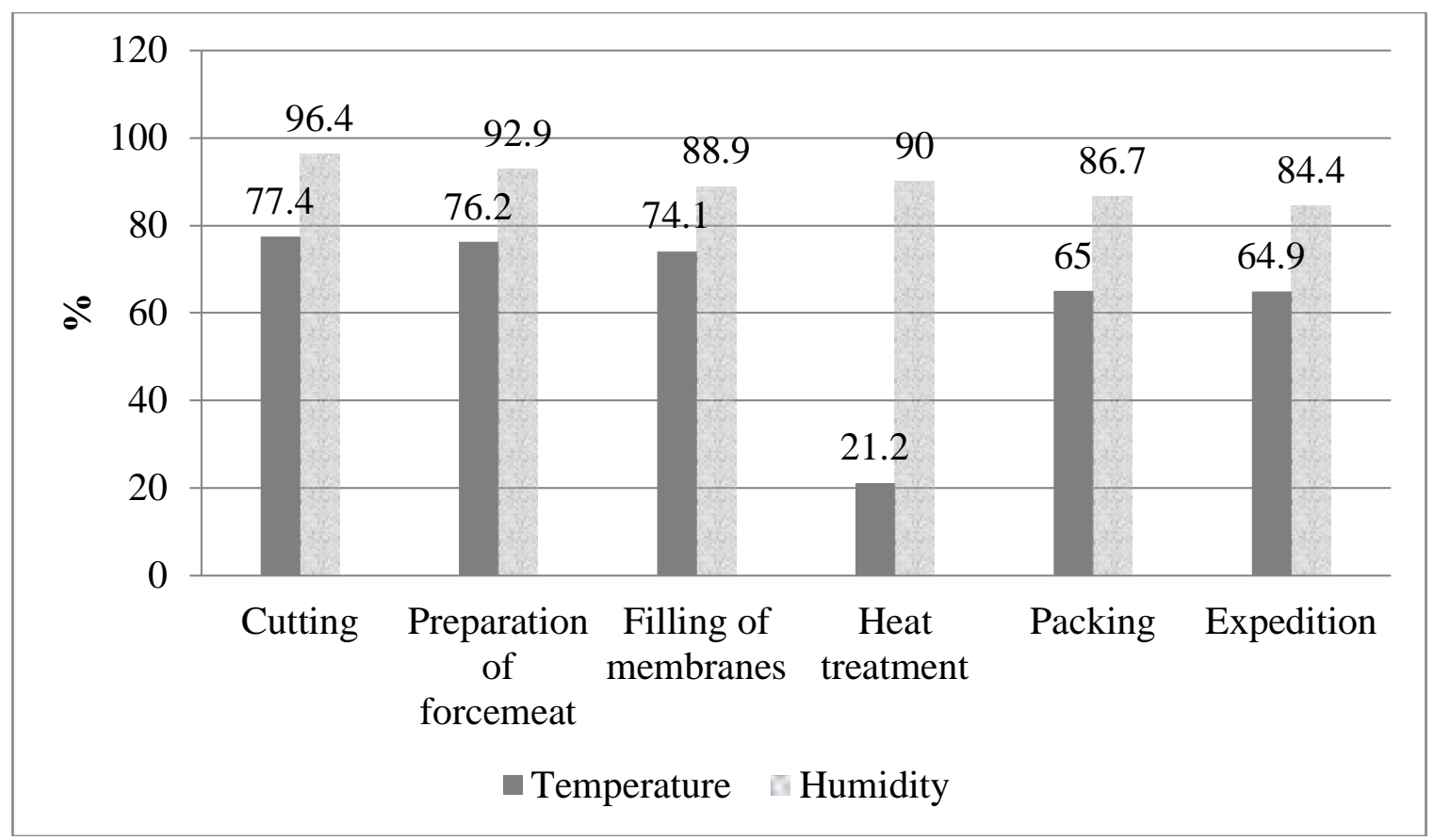

Fig.2:- The microclimate parameters in the different segments of meat enterprises

The mean temperature in the investigated enterprises were below the sanitary $\left(15-26^{\circ} \mathrm{C}\right)$ norms, except for the heating segment. Thus, the lowest mean air temperature (table 1) were registered in the cutting segment $\left(12,6^{\circ} \mathrm{C} \pm\right.$ $\left.0,5^{\circ} \mathrm{C}\right)$ and in the forcemeat preparation segment $\left(12,3^{\circ} \mathrm{C} \pm 0,47^{\circ} \mathrm{C}\right)$, where occupational conditions can be classified as harmful: class III, grade 1 according to the methodical recommendation of 10.03.2008. The occupational conditions at the enterprises 1 and 3 , in the cutting segment, can be characterized as harmful: class III, grade 2 with the mean temperature of $10.8^{\circ} \mathrm{C} \pm 0.16^{\circ} \mathrm{C}$ and $8.3^{\circ} \mathrm{C} \pm 1.64^{\circ} \mathrm{C}$ respectively (table 1 ).

Table 1:- Mean temperature in workplaces of meat industry enterprises $\left({ }^{\circ} \mathrm{C}\right)$

\begin{tabular}{|c|c|c|c|c|c|}
\hline \multirow[b]{2}{*}{ segment } & \multicolumn{4}{|c|}{ enterprises: } & \multirow{2}{*}{$\begin{array}{c}\mathrm{M} \pm \mathrm{m} \\
\text { all enterprises }\end{array}$} \\
\hline & 1 & 2 & 3 & 4 & \\
\hline cutting & $10,8 \pm 0,16$ & $14,2 \pm 0,13$ & $8,3 \pm 1,64$ & $16,0 \pm 1,0$ & $12,6 \pm 0,5$ \\
\hline preparation of forcemeat & $11,0 \pm 0,13$ & $14,6 \pm 0,13$ & $10,0 \pm 0,48$ & $17,5 \pm 1,35$ & $12,3 \pm 0,47$ \\
\hline filling the membranes & $11,2 \pm 0,17$ & $15,3 \pm 0,19$ & $12,7 \pm 0,3$ & $15,8 \pm 1,1$ & $12,8 \pm 0,44$ \\
\hline heat treatment & $17,1 \pm 0,18$ & $15,3 \pm 0,13$ & $13,8 \pm 1,15$ & $20,0 \pm 0,8$ & $17,4 \pm 0,41$ \\
\hline packing & $10,7 \pm 0,23$ & $12,3 \pm 0,25$ & $9,0 \pm 0,58$ & $18,1 \pm 0,86$ & $13,5 \pm 0,53$ \\
\hline $\begin{array}{lll}\begin{array}{l}\text { shipment } \\
\text { products }\end{array} & \text { of meat } \\
\end{array}$ & $108 \pm 0,31$ & $10,5 \pm 0,63$ & $12,1 \pm 1,61$ & $16,3 \pm 0,37$ & $12,7 \pm 0,38$ \\
\hline
\end{tabular}

The noise level, created by the equipment and refrigeration units, systems of air cooling, exceeds the admissible level for $40 \%$ of workplaces. Results of measurements have shown exceedance of admissible noise level on 2-5 $\mathrm{dBA}$ in segments of sausages production and smoked products. In the segments of offal, preparation of forcemeat and equipment maintenance the noise level on 18-24 dBA exceeds the sanitary norms. Scientific data indicates that noise level may vary depending on level of production, condition of equipment, processes involved and type of noise caused and lead to occupational related noise-induced hearing loss, reproductive impact, lowered birth rate and increase in blood pressure (Picard M., 2008; Pascolini D., 2009).

The noise levels in the workplaces are presented in Table 2. The highest noise level was registered for the heat treatment segment $(84.6 \pm 0.7 \mathrm{dBA})$, laundry $(82.7 \pm 1.1 \mathrm{dBA})$ and preparation of forcemeat $(79.7 \pm 0.4 \mathrm{dBA})$, and the lowest for the shiping of meat products segment $(67,7 \pm 2,5 \mathrm{dBA})$. Exseedance the sanitary $(80 \mathrm{dBA})$ norms were characteristic for such segments, as cutting, preparation of forcemeat, heat treatment and laundry. 
Table 2:- The noise levels in the workplaces in some segments of meat processing $(\mathrm{M} \pm \mathrm{m}, \mathrm{dBA})$

\begin{tabular}{|l|c|c|c|c|c|}
\hline \multirow{2}{*}{ segment } & \multicolumn{4}{c|}{ enterprises: } & \multirow{2}{*}{$\begin{array}{c}\text { M } \pm \text { m, } \\
\text { enterprises }\end{array}$} \\
\cline { 2 - 6 } & 1 & 2 & 3 & 4 & $75,1 \pm 0,7$ \\
\hline cutting & $74,7 \pm 0,4$ & $72,6 \pm 0,6$ & $73,7 \pm 1,5$ & $85,8 \pm 1,4$ & $79,7 \pm 0,4$ \\
\hline preparation of forcemeat & $78,6 \pm 0,3$ & $77,2 \pm 0,04$ & $81,8 \pm 0,9$ & $87,0 \pm 1,9$ & $75,1 \pm 0,4$ \\
\hline filling the membranes & $73,5 \pm 0,3$ & $80,0 \pm 0,07$ & $75,7 \pm 0,7$ & $75,3 \pm 3,4$ & $84,6 \pm 0,7$ \\
\hline heat treatment & $84,3 \pm 0,5$ & $88,4 \pm 0,03$ & $82,0 \pm 0,3$ & $85,8 \pm 3,5$ & $75,0 \pm 0,6$ \\
\hline packing & $78,6 \pm 0,4$ & $70,5 \pm 0,2$ & $71,2 \pm 0,8$ & $74,7 \pm 0,9$ & $67,7 \pm 2,5$ \\
\hline shipment of meat products & - & $75,9 \pm 0,11$ & $56,0 \pm 4,0$ & - & $82,7 \pm 1,1$ \\
\hline laundry & $82,2 \pm 0,1$ & $86,0 \pm 0,1$ & - & $76,0 \pm 4,0$ & 82,0 \\
\hline
\end{tabular}

The analysis of data on incidence of temporary disability among workers was carried out for establishing of features of these diseases in connection with impact of occupational factors. It has been established that the frequency of temporary disability fluctuated by years. So, the mean cases of diseases (fig. 3) during the studied period varied from $59,73 \pm 10,3$ to $32,01 \pm 8,7$ cases per 100 workers that indicates a tendency to decreasing, on average 6,7 cases per 100 workers $\left(R^{2}=0,95\right)$. This regularity was characteristic for all investigated enterprises, except for the enterprise 1, in which for this period the small tendency of growth, on average 2,1 cases of disability per 100 workers was recorded $\left(\mathrm{R}^{2}=1\right)$. According to the obtained data, in 2015 the number of cases decreases by 32,0 and 15,34 cases per 100 workers. The decreasing of disease frequency registered in recent years was connected with the measures taken for improvement of working conditions in the occupational area. Results of our study coincide with the data obtained in researches (Farcas E., 2011; Hristova Lidiya, 2016; Starodubov V.I., 2001).

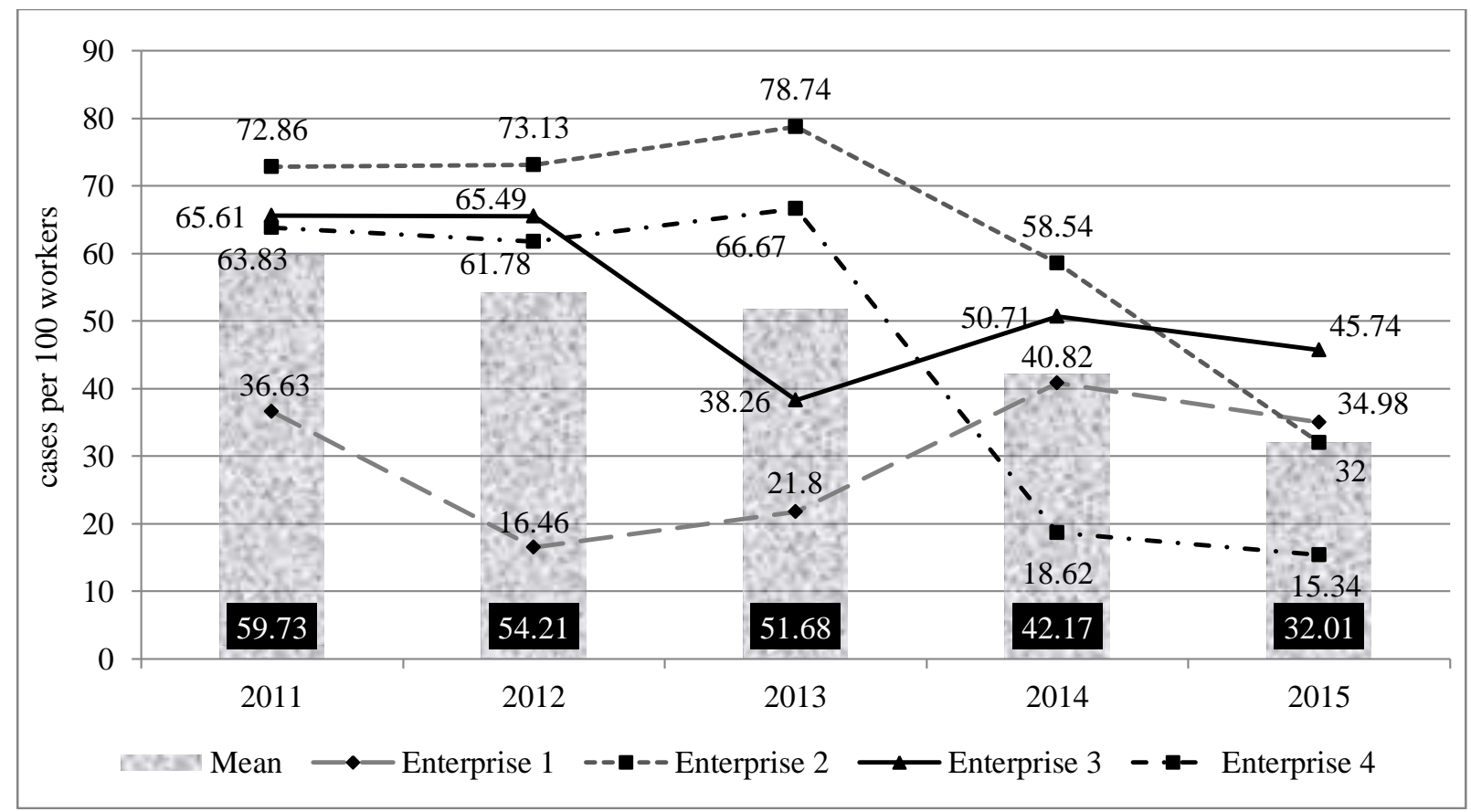

Fig 3:-The frecvency of temporary disability (number of cases per 100 workers)

On enterprises 1 and 3 the opposite situation was observed. For the last 3 years the increasing in number of diseases cases - from 21,8 to 34,98 and from 38,26 to 45,74 cases per 100 workers respectively was registered. It is possible to suggest that implementation of preventive measures for health risk reduction at these enterprises was insufficiently effective.

Assessment of the duration of disease (figure 4) expressed by the number of days with temporary disability per 100 workers was carried out. According to obtained data, the same regularities which are characteristic for the disease frequency indicator was established. So, the average value of diseases duration during 2011-2015 had decreased from $719,9 \pm 192,9$ to $414,4 \pm 192,9$ days per 100 workers, with a tendency to decrease on average for 77,05 days per 
100 workers $\left(\mathrm{R}^{2}=0,81\right)$. The highest mean number of days with temporary disability was registered on enterprises 2 and 3 , respectively $1233,07 \pm 171,2$ and $731,67 \pm 101,2$ days per 100 workers. The smallest average value of this indicator was characteristic for enterprise $1(166,67 \pm 56,5$ days per 100 workers).

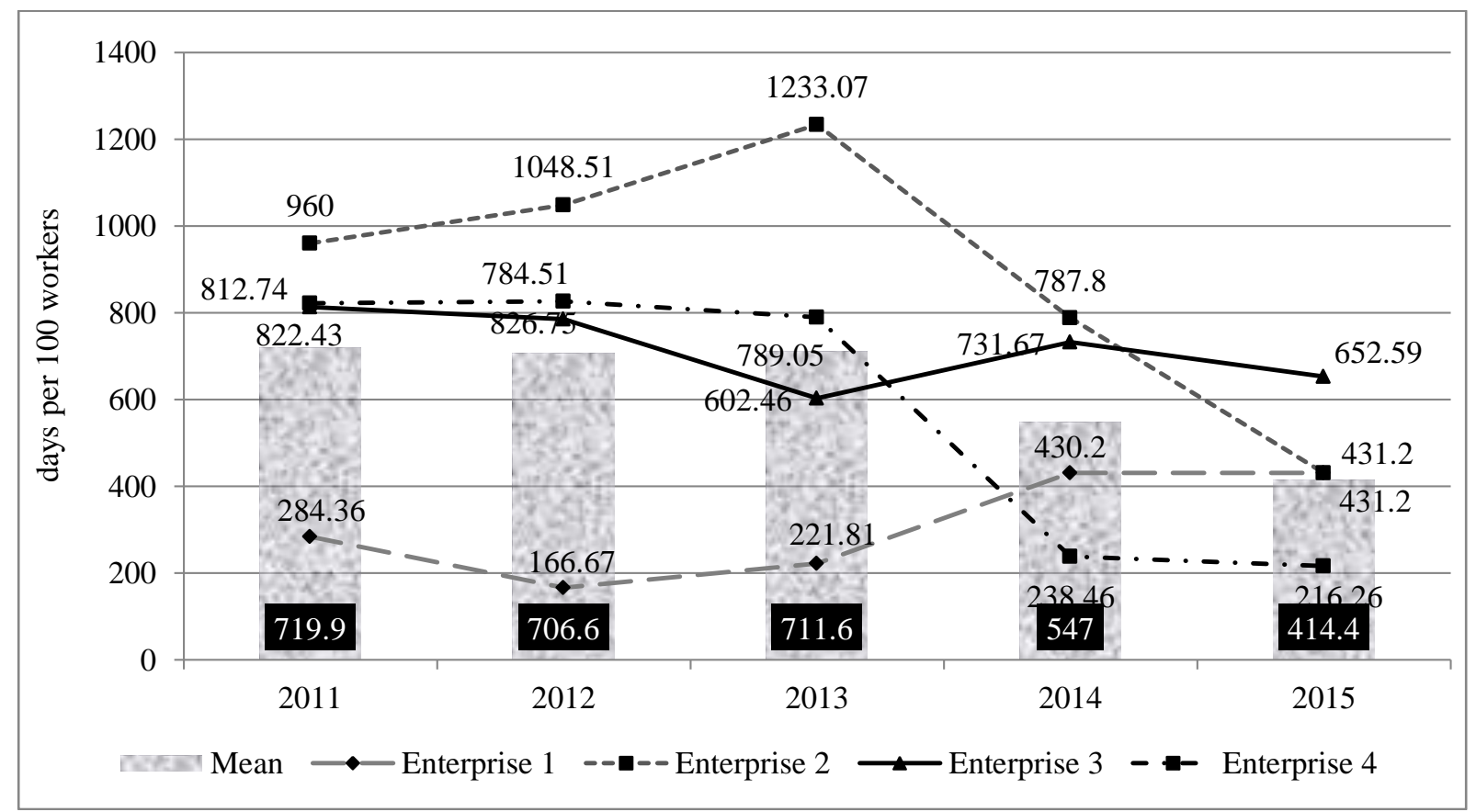

Fig.4:- Duration of disease (number of days with temporary disability per 100 workers).

Other indicator which characterizes incidence with temporary disability of workers is the average duration of one case disease. During the study period the average duration of one case of disability increased. The mean annual increasing was 0,3 days for one case $\left(R^{2}=0,47\right)$ (figure 5). The established of growth is more significant for enterprises 1 and 3 when annual averages increasing was 0,52 and 0,48 days for one case $\left(R^{2}=0,58\right.$ and $R^{2}=0,23$, respectively). This fact indicates that the workers consult a doctor only at a serious illness demanding longer period of treatment and recovery.

For establishment of features of pathologies associated with the occupations is important to study structure incidence of temporary disability. In this context, the mean data concerning the distribution of nosologies with temporary incapacity, both according to the frequency and the severity of disease indicate that the first place belongs to diseases of the respiratory system, second place - to the circulatory system diseases, and third place belongs to the diseases of the digestive system, osteoarticular and traumatic lesions. 


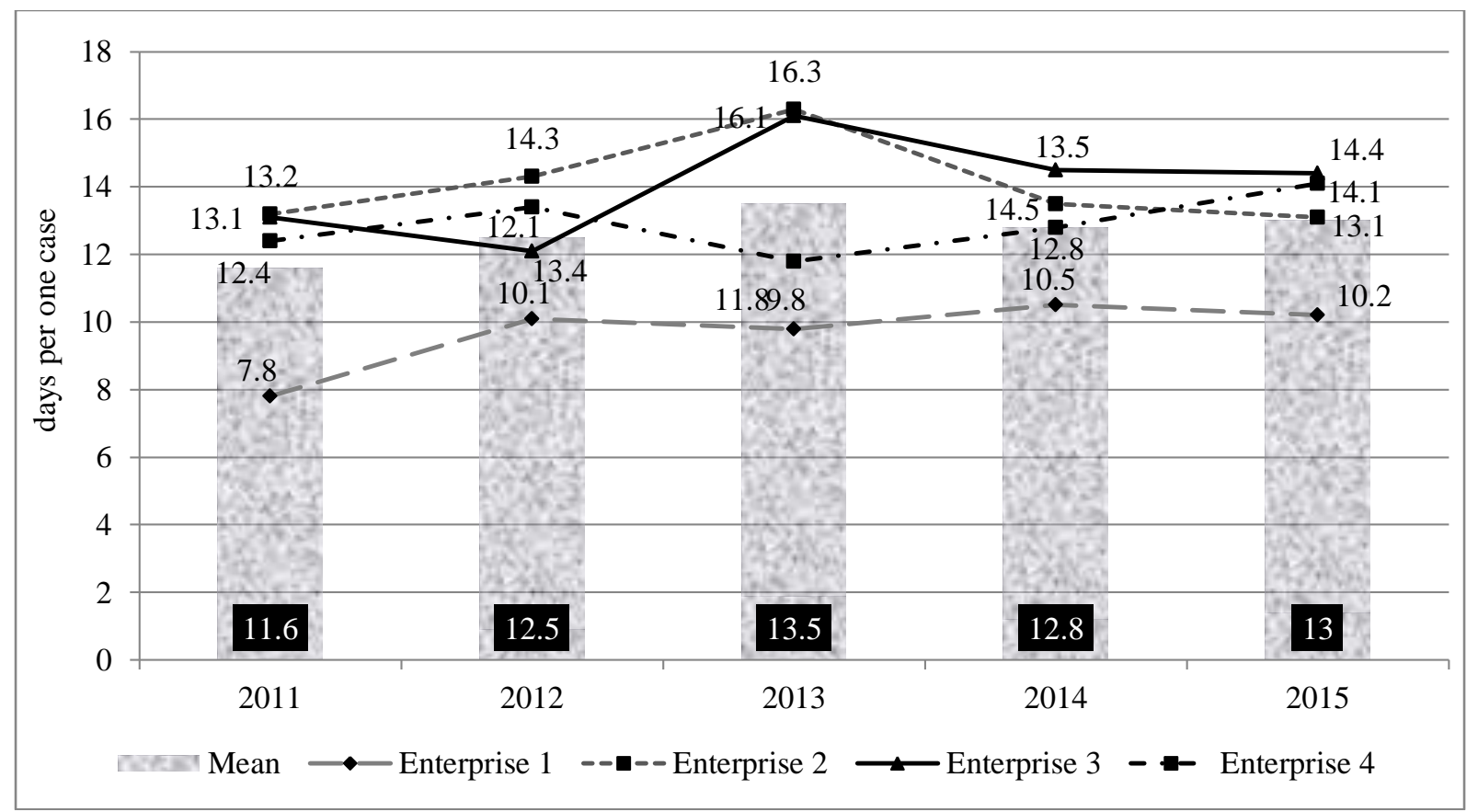

Fig 5:- The average duration of one case disease (days per one case)

So, in average were registered $3.54 \pm 0.7$ cases of osteoarticular diseases per 100 workers $55.2 \pm 12.9$ days/100 workers) and $3.02 \pm 0.4$ cases of traumatic lesions per 100 workers ( $48.75 \pm 10.3$ days/100 workers). Generally, the mentioned diseases were registered for the employees who worked in the segments of forcemeat preparation, the filling of membranes with sausages.

The obtained data indicate the need of development and implementation of preventive measures (WHO. Media centre 2014).

\section{Conclusion:-}

The occupational environment of the meat industry is characterized by a complex of unfavorable risk factors (microclimatic parameters, noise exposure), which determines the probability of their impact on the health workers. Morbidity with temporary incapacity at the investigated enterprises presents some variability in time. The frequency index averaged 6.7 cases per 100 workers $\left(\mathrm{R}^{2}=0.95\right)$ during the studied period, and the duration index averaged 77.0 days per 100 workers $\left(\mathrm{R}^{2}=0.95\right)$.

Increasing of the mean disease duration of a case with temporary incapacity, in annual was average 0.3 days per one case of illness. The obtained regularity was characteristic for all studied occupational area and nosologies, which indicates that the workers consult a doctor only at a serious illness demanding longer period of treatment and recovery.

The morbidity features indicate the need to develop and to implement measures for improving the working conditions and reducing the impact on health of the occupational risk factors. 


\section{References:-}

1. Banjo T.A., Onilude A.A., Amoo A.O.J. , Busari A., Ogundahunsi O.A., $\quad$ Olooto W.E., Familoni O.B., Amballi A.A., Oyelekan A.A.A., Abiodun O.A. (2013): Occupational Health Hazards Among Abattoir Workers In Abeokuta. Academia Arena, 5(10). Available at:http://www.sciencepub.net/academia.

2. Berry J. van Holland, Remko Soer, Michiel R. de Boer, Michiel F. Reneman, and Sandra Brouwer. (2015): Workers' Health Surveillance in the Meat Processing Industry: Work and Health Indicators Associated with Work Ability. J Occup Rehabil.; 25(3): 618-626.

3. Campbell D.S. (1999): Health hazards in the meatpacking industry. Occup Med, 4(2):351-372.

4. Farcas E. (2011): Aspects regarding morbidity with temporary disability of workers in Romania between 19952008. Medical Life, 3. Available at: http://www.viata-medicala.ro/*article ID_2738-dArt.html (in Romanian).

5. Health and Safety Guidance Notes for the Meat Industry, British Meat Processors Association, 2014,222 p.

6. Hristova Lidiya, Filippidou Elisavet-Christina, Chernaeva Mariya, Tsacheva Nevena.(2016): Diseases with temporary disability of the respiratory system at persons working in hospitals. Ann Transl Med., 4(22): AB025. Available at: https://www.ncbi.nlm.nih.gov/pmc/articles/PMC5159368/.

7. Harmse L. Johannes, Engelbrecht Jacobus C. and Bekker Jahan L. (2016): The impact of physical and ergonomic hazards on poultry abattoir processing workers: a review. Int J Environ Res Public Health, 13(2):197. Available at: https:// www.ncbi.nlm.nih.gov/pmc/artickes/PMC4772217/.

8. Mansi Suliman, Milosavljevic Stephan, Tumilty Steve, Hendrick Paul and Baxter G David. (2013): Use of pedometer-driven walking to promote physical activity and improve health-related quality of life among meat processing workers: a feasibility trial. Health and Quality of Life Outcomes, 11:185.

9. 9. McLean D., _Cheng S., M 't, Woodward A. and Pearce N.( 2004): Mortality and cancer incidence in New Zealand meat workers. Occup Environ Med, 61(6): 541-547.

10. Picard M., Girard S.A., Simard M., Larocque R., Leroux T., Turcotte F. (2008): Association of work-related accidents with noise exposure in the workplace and noise-induced hearing loss based on the experience of some 240,000 person-years of observation. Anal. Accid. Prev., 40:1644-1652.

11. Pascolini D., Smith A. (2009): Hearing impairment in 2008: a compilation of available epidemiological studies. International Journal of Audiology, 48:473-485.

12. Rodilla José María Ramada, Bistué Ignasi Manent, Pujadas Consol Serra. (2016): Musculoskeletal disorders and temporary disability: frequency and duration in Catalonia, 2007-2010. BMJ; Ocipational \& Environmental Medicine, volum 73, Issue Suppl 1. Available at: http://oem.bmj.com/content/73/Suppl_1/A70.1.

13. Shaprov M.N., Misyuryaev V.Yu., Martynov I.S., Guzenko E.Yu. Special assessment of working conditions and safety of workers in agro-industrial complex. Available at: https://cyberleninka.ru/article/n/spetsialnayaotsenka-usloviy-truda-i-bezopasnost-rabotnikov-apk.

14. Starodubov V.I., Kalininskaia A.A., Ĕ̊gin L.E., Dzugaev K.G. (2001): Incidence of diseases with temporary disability among dentists. Probl Sotsialnoi Gig Zdravookhranenniiai Istor Med., 4:14-8.

15. WHO. Media centre (2014). Protecting workers' health. Fact sheet N 389 . Available at: http://www.who.int/mediacentre/factsheets/fs389/en/. 